\title{
The Effective Mistake in Iran Fiqh and Jurisprudence
}

\author{
Fariba Khalijian $^{1} \&$ Sayyed Morteza Naeemi ${ }^{2}$ \\ ${ }^{1}$ Department of Law, Human ities Faculty, Islamic A zad University, Rasht Branch, Rasht, Iran \\ ${ }^{2}$ Department of Law, Human ities Faculty, Islamic A zad University, Bandare Anzali Branch, Anzali, Iran \\ Correspondence: Fariba Khalijian, Department of Law, Humanities Faculty, Islamic Azad University, Rasht \\ Branch, Rasht, Iran.
}

Received: June 16, 2016 Accepted: July 18, 2016 Online Published: July 31, 2016

doi:10.5539/jpl.v9n6p203 URL: http://dx.doi.org/10.5539/jpl.v9n6p 203

\begin{abstract}
The effect of mistakes on contract depends on certain conditions of which the most salient one is the fundamentality of mistakes. Magistrates must refer to contract parties' intentionsto identify the domain of the fundamental mistakes and their effects on the contract. Is the domain of the effective mistakes limited to the subject and important characteristics of the contract parties? Or can we find a unity of measurements among the characteristics of mistakes causing nullification, which incorporate all or at least most of the proofs of mistakes causing nullification? Why do in some cases, mistakes result in nullification and in others the cancel right and in some other ones no effects in contracts? The civil law, in articles 200 and 201, limits the domain of mistakes to "the contract itself" and "the important feature of contract parties". If we consider the base of the mistake effectsitsfundamentality, the mistake domain includes any mistakes in all basic elements of contracts which are the main reasons for making the contracts and mutual consent. Its condition is that the description of fundamentality is clearly or implicitly mentionedin the contract. Also the extent of effect of mistakes in contracts , depends on the importance of mistaken element in the opinions of contract parties. Some of the elements of the contract are related to mutual consent and mistakes in them result in problems in intention and nullify ing the contract. Some other elements are not related to mutual consent and they are not in the domain of intention of the contract. If mistakes in them comes to the domain of mutual consent, naturally it leads to the authority of cancelling the contract.
\end{abstract}

Keywords: mistake, contract, contract subject, basic features

\section{Introduction}

For forming any contract, the intention and satisfaction of contract parties is necessary. Also they must have reliable intentions. But not always, the intentions and satisfaction of contract parties have credits. It is possible that some factors result in their nullify ing or problems. In such cases, depending on their importance degree or nature, the credit of the contract is affected. In some cases, the legislator consider the intention and satisfaction without credit. Obligation and mistake are of such cases. A mistake is defined as the contract parties' wrong imagination. In other words, mistakes mean the wrong imagination of contract parties about one of the contract ele ments. The subject of this contract is reviewing the effects of mistakes on contracts. In various rules of the civil law, some mistakes are mentioned which result in contract nullification. Also, there are some cases which result in giving the cancel authority of one of the contract parties. Also, jurists mentions many cases in which mistakes in contracts have no effect on its credit. These cases are scattered in the law and in different articles. Also some jurists add to evidences of mistakes; for example they say that mistakes on commitment reasons also nullify contracts. Now there is a question: Can we find a common domain among evidences in mistakes nullifying contracts? Also this problem should be mentioned that what the difference among mistakes resulting in nullifying contracts or establishing the right of canceling contracts is? This article deals with how mistakes affect the results of contracts and providence of genuine will of con tract parties?

Mistakes in contract type, contract nature, contract subject, contract parties and commitment reasons are evidences of mistakes nullify ing contracts. If we consider the root of mistakes its being basic, the domain of mistakes nullifying contracts includes all basic mistakes which are main reasons for forming contracts and mutual consent. This is the case if being basic is explicitly or implicitly mentioned in the contract. Also the extent of mistakes in contracts depends on the importance of the element in opin ions of contract parties. So me of 
elements of contracts are based on mutual consent and mistakes in them result in nullifying the contract. Some others are not mutual contract conditions and are not under the domain of contract intention. Mistakes in them if resulting in disturbance of mutual consent, results in rendering the canceling right to make up for losses. Some other mistakes have no effect on the contract. Based on these facts, mistakes are divided into three categories: 1mistakes nullifying contracts 2 - mistakes giving the cancelling right 3-mistakes with no effects.

\section{Mistakes Nullifying Contracts}

Some mistakes damage the main elements of contracts. As a result, if you act based on them, the contract is nullified. Sometimes it is possible that mistakes occur in contract elements which are of mutual consent conditions and are under the domain of intention. Mistakes in these elements, harm the intention and cause nullification of contracts. All that a person imagined of dealing and is satisfied with is not under the domain of intention. Only those elements of contracts which are considered basic in contract parties views are under the domain of intention. Mistakes in such cases nullify contracts since they harm intentions . (Shahidi, 1998,167). In Islamic Fiqh, the basis for forming the contract is contract parties' intentions. Based on the intentions, all contracts in the world of credit are formed. Sheikh Ansari, regarding the conditions of contracting parties states that intention of one of the conditions of contracting parties. (Ansari,2007, 117). In Fiqh, the famous rule "Contracts depending on intentions" indicates the main role of intention not only in forming contracts but also in limitations of their effects. Compilers of Iran civil rights compiled the law based on Jafari Fiqh and famous views of Faqihs. As a result, the main source of total of Civil law is formed by Imamieh Fiqh. Some mistakes damage the main elements of contracts. As a result, if you act based on them, the contract is nullified. Mistakes in contract type, contract nature, contract subject, contract parties and commitment reasons are evidences of mistakes nullifying contracts.

In Imamieh Fiqh, as a general regulation, in two cases mistakes result in nullify ing contracts: 1- mistakes obstructing establishment of mutual consent. (mistakes in type and nature of contracts) and 2- mistakes obstructing the achievement of mutual consent (mistakes in deal subject, in contract party and in commitment reason). (Mohaqeq Damad, 2012,164:2).

Hereby mentioning evidences of mistakes nullifying contracts in Iran fiqh and jurisprudence, we search for the answers to this question: "Can we find a unity of measurement in evidences of mistakes nullifying contracts which incorporates all or at least most of mistakes nullify ing contracts and is not limited to explicit articles in civil law, so that they can be used as a general frame work when the rule does not mention them clearly?"

\subsection{Mistakes Obstructing the Establishment of Mutual Consent (Disagreementof Compliance and Acceptance)}

In this situation, mistakes result in disagreement between the contract parties resolutions and between compliance and acceptance. In this situation, since the disagreement between contract parties resolutions is one of the main factors of forming the contract, not achieving it results in not having any contract. The contract which apparently exists is just two writings and announcements of disagreeing resolutions. Apparently, the civil law states that the source of invoking to mistakes is at least the establishment of the contract in appearance. In this situation, although in fact and in demonstration, mutual consent is not established and there was a mistake in the very first stage for mutual consents, until this is not proved, the contract has its legal credit.

For example, in a written document between contract parties which apparently is about the transmission of interests, while the party can not prove the genuine intention of transmission, the rent contract has its legal rights . (Zakeri, 2011,222)

Regarding the nature of affecting of mistakes in contract type and nature of contract subject, since they result in disagreement between compliance and acceptance of contracts or disagreement between resolutions, it nullifies the contract. In other words, mistakes in these two cases obstruct the parties from reaching mutual consent. We subsequently explain them:

\subsubsection{Mistake in "Type of Contract"}

If the parties make mistakes in type of contract, the contract is nullified. For example, if a party wants to rent his house and by mistake establishes its sale and the other party accepts its sale, the contract must be considered nullified. Since the contract type is of the main elements of contract and must be under intentionand parties must consent on its type. If the contract type is not of the intention of writing and consent of parties, there is no contract. (Shahidi, 1998,168). The reason for this is that establishing a legal type which is different of the nature of the other party's goal, is under possession of the parties intention. The article 194 of civil law in this case states that: Other words, references, and actions by which the contract parties deal with each other, must be under consent, so that a partner accepts the contract which is of the intention of the other party, or the deal is 
nullified.

Also the Imamieh Faqihs state that mistakes in the contract type nullifies the contract based on disagreement between implicit and explicit resolutions or in other words disagreement between establishment and compliance. For example, a person wants to sell his rug to another person and the other person imag ines that he is donating his rug and the price is just a formality. The contract must be nullified because of disagreement between compliance and acceptance of contract (Najafi,1997,279). So each of contract parties must intend to write the same contract that the other one intends to. Obviously, regarding that the contract type which is in the mind of one of the contract parties, and this paradox in type results in disagreement between co mp liance and acceptance, there is practically no contract, since one of the necessities of agreement between resolutions in agreement in the type of contract. (Article 194 Civil Law)

\subsubsection{Mistakes in Identity of Contracts}

The Iran Civil law does not state anything regarding mistakes in contract nature. Dr.Emami con sider this mistake, the one on the contract subject and for nullifying the contract, he invokes to article 200 of civil law. (Emami, 1999,178:1). However, it must be noticed that this interpretation is incorrect, since there is a major difference between mistakes in subject itself and the ones in contract nature. Regarding the mistakes in subjects, the issues of resolution of contract parties is a single issue and the contract is about it while in mistakes about contract identity, the issues of contract parties resolution are not a single issue and are two different issues. (Ansaqri:1996,129). In other words, in the mistakes in contract types, the compliance and acceptance deal with one issue, while there is a mistake in basic description or facts. However, in the mistakes in the identity of contract, the compliance and acceptance deal with two different issues and there is no agreement between them. Sometimes, the basis of nullify ing the contract because of mistakes in identity of deal, is article 339 . This article states that after agreement of seller and the costumer on the sale subject and its price, the contract is "complied and accepted". So the civil law also states that the agreement of contract parties' resolutions about a single subject is essential, and if because of a mistake, each contract parties resolves a different subject from the other's ; the contract is nullified since there is disagree ment between compliance and acceptance. (Gharibeh,2005, 84,47). Sometimes, mistakes in identity of contracts nullify the contract because of causing inconsistency between goal and reality. For instance, the parties bargain on a vase since they think it is an antique. However it is revealed that it is not an antique they were wrong. In this case the goal of parties is different from the reality. (Shahidi; 1998, 170).

Also the Imamieh faqihs consider the contract nullified when there is a mistake about the identity of subject and parties interpret two different subjects from a single contract. They consider this mistake an obstruction in two parties' agree ment because of dis agreement between the compliance and acceptance. For example, a seller wants to sell the first floor of an apartment and the costumer accepts the purchase of the third floor of that apartment. There is no contract here, since the compliance and acceptance are not on a same subject.

\subsection{Mistakes Obstructing Mutual Consent Achievement (Obstructing the Agreement between Intention and Reality)}

Sometimes, mistakes result in disagreement between what is intended and what happens. "What was intended did not happen and what happened was not intended.", and the mistake obstructs the effectiveness of intention of parties' writing of contract. Faqihs state that in this situation, we must notice that contract elements exist or are present, but the occurred mistake obstructs achieving the contract and as a result the contract is nullified. (Mohaqeq Damad, 2012,164:2). These mistakes nullify contracts: The mistakes in "contract subject" (Article 200,civil law) the mistakes in " contract partner' who is the main reason of contract (article 201 civil law), the mistakes in reason of commitment, since they result in disagreement between contract and intention. In other words, apparently the contract is formed and mutual consent is achieved. But the occurrence of mistakes in parties and the subject itself (the main descriptions which are the main reasons of contracts) result in disobeying " contract obeying the intentions" and " What was intended did not happen and what happened was not intended." Happens.

\subsubsection{Mistakes in "Contract Subjects"}

Article 200 of civil law deals with mistakes in " deal subjects" and states that: " Mistakes result in deals losing their in fluence when they are related to deal subjects." What is meant by deal subject itself?

\subsubsection{The Comments about the "Deal Subject Itself"}

The jurists generally gave 4 theories about "deal subject itself". Based on them, it is defined as:

1) Mistake in the "object of deal": Dr. Emami argues that a mistake in the "deal subject itself" is a mistake in the 
object of the deal. This means that everything is formed of a series of materials which constitute the $n$ ature of that thing. So the object is the material constituting it. Like a table whose constituting material is wood or a ring whose nature and physics are compromised of gold or silver. In this sense, the object is used against the its descriptions and payments and these descriptions and payments are not part of the nature of the thing and not considered in the concept of the thing. Since mistakes in "deal subject itself" are mistakes in the material compromising the deal and in fact forms its nature. (Emami, 1999,197).

Accepting this theory, if a desk is bought instead of a chair or a donkey instead of a horse, the deal is correct since the main material of these things are the same and as a result there was no effective mistake and the subject of contract and intention is the same. (Katusian,1995,428:1). Accepting this theory results in putting attributes whether primary or secondary in addition to the object. The result is the deal being correct in primary attributes even if there is a mistake.

2) Mistakes in "the identity of deal object": Some jurists, consider the article 200 about the issue when each of the deal parties wants something which is not the intention of another one and consequently the agreement of resolution about an issue and a certain evidence does not exist. Mostafa Adl states that "if somebody offers another person to sell a house he has at a certain price, and the other party accepts the offer imagining that the seller is offering the sale of his own house in Tabriz, the deal is nullif ied." (Asl,1994,118), since it obstructs the agreement of resolutions which is the basis of correctness of deals based on articles 183,194 and 339 of civil law.

3) Mistake in "primary attributes": Some jurists in commenting on article 200, considered "deal subject itself" the main attributes of the subject, following the views of late faqihs like Sheikh Ansari and also doctors and France judicial procedure. Based on this view, all properties are the total of all properties distinguishing them from all other things based on the common view. So we must not put the attributes of the object of deal against the deal itself (in concept of object). We must observe which property is primary and constitutes the nature of the deal or its absence changes the deal subject and which one is secondary or its modification does not change the deal subject. (Katuzian, 1995,442:1). Also in fiqh, especially based on the late views and opinions of faqihs, mistakes in the nature of the deal is considered mistake in primary properties which form the reality and base of the deal object, and any mistakes in it results in nullify ing the contract. Naiini, regard ing this issue, states that the rule of " Contracts obeying the goals", must be used here, for example what the seller intended and paid the money for it is nullified and what is here is not the goal and nothing is paid for it. (Naiini, 1994, 135: 2).

So, in all deals it must be observed that what point of view the parties look at the deal subject from and because of what property they have made the contract. This feature must be considered the natural attributes and the mutual consent conditions.

4) Mistakes in the "common nature of the subject": Based on this view, the mistake in the common nature of the subject of the deal, is the mistake in features which commonly results in distinguishing the deal object from other ones. For example, purchase of male shoes instead of female ones and purchase of silver like spoons or forks instead of silver and buying the new things instead of antiques are examples of mistakes in common nature of subjects. (Musavi, 1393,292). Based on this fact, mistakes in common or typical nature is when the deal party's goal is different form the deal object commonly and typically. And simply the common view considers them two different things whether they are two different things or not. So, based on this view, the article 200 deals with the mistake in common nature of the deal (Safaee, 1349,105).

In the abovementioned views, it seems that the object itself incorporatesnot only the object in deal, but also its constituting materials, and its natural and main features in the deal which in fact form the contract. In other words, the description of the deal issue which is the main reason of forming the contract is known as the "deal subject itself" ; since paying the price for the main description is done.

\subsubsection{The Conditions of Effects of Mistake in "Deal Subject Itself"}

In articles 200 and 201, jurists made two conditions necessary for effects of mistakes in contracts. First, the mistake should be the main reason making the contract. The main reason is something that make the basis of forming contracts in contracting party so that its absence results in absence of the contract formation, and the second condition is that mistakes must be under the domain of mutual consent and contract must be formed based on that wrong imagination. So, mistakes regarding inner intentions of contract parties, have no effect until they are not expressed even implicitly.

After recognizing the mistake concepts in "deal subject itself"and knowing the conditions of mistake effects on the destiny of contract which happened in the domain of mutual consent while forming the contract, now the main issue is making certain of practicing such mistakes. 
In Islamic fiqh, the basis of forming contracts, is intentions of contract parties and based on them, all contracts are formed in the world of credits. When contract parties imag ine certain characteristics and attributes as "main properties" in the deal subject, and the deal is based on them, and afterwards it is revealed that the imagined main characteristic did not exist and a main mistake occurred. naturally what remains is not intended by contract parties, since intentions of contract parties is committed to existence of that primary attribute and based on the rule of "committed with no commitment", now that that attribute does not exist, obviously the things that exist are not intended by contract parties and on the other hand the intention of contract parties is not achieved because of absence of intention. So, in all situations in which forming contracts have main mistakes, faqihs consider the deal nullified and state their deduction as "What was intended did not happen and what happened was not intended." And this is in other words the rule of " contracts obeying intentions". (Naeeni 1373,135:2)

Also, in Iran jurisprudence, some jurists deduct thatthe word " Ed Manfudh" in article 200 civil law is nullification since mistakes in deal subject itself, are related to intentions and mistakes in that criterion harm intentions. They also refer to unity of scale in articles 353 and 762 civil laws which point to nullification. (Shahidi,1380,165, Rah Pik,1376,157). This view is based on the faqihs' ones and is for completing the abovementioned reasons which are explicit evidence of contracts not reaching intentions in this issue (mistakes in deal subject itself). (Safaee,1375,99)

It seems that the nullification theory regarding the certainty of making the mistakes in deal subject itself in the civil law, is superior to other views since this is sue is an explicit example of contract not reaching its goal, since the intentions of parties do not correspond to reality. So, the occurrence of mistakes in the subject itself results in problems in materials of contract formation in the view of contract formers and consequently the intentions of contracts are not achieved and contracts are nullified.

\subsubsection{Mistakes in "The Contract Party Character"}

The Article 201 civil law states that:"Mistakes in contract party characters do not harm the origins of contract unless when the contract parties are the major reason of contract." Mistakes in contract parties character occur when one of contract parties, imagines something wrong about the character of the other party and thinks wrong about them. In such cases if this wrong imagination becomes basis of the contract, so that if the party knew the truth, the contract would not form, this mistake affect the result of contract and the contract credits is referred based on the verdict of article 201 civil law. Mistakes in character of contract partner could be in their personal identity, civil identity or main characteristics. Now there is a question: is a mistake in character only in his personal character or does it also include their main characteristics?

It seems that any time a mistake disturbs the main description and the main reason of forming a contract, it nullifies contracts since this results in disagreement between compliance and acceptance and contract not reaching its goal. This is also because mistakes in contract party's character, just like the subject itself, is an evidence of mistake in main features and main reason of contract. The main reason is a feature forming the basis of contract and is for reaching the desired goal. However, jurists make an exception in marriage contracts and only render cancel right for mistakes in them. The condition of effect of mistakes in main features is that the noticed features must be under the domain of mutual consent explicitly, implicitly, or by referring to circu mstances or common views. If not, mistakes in descriptions, have no effect in contracts.

\subsubsection{Mistakes in Commitment Reason}

The title of " commitment reason" is not explicitly mentioned in civil law. In articles 200 and 201,only the subject itself and character of contract parties (if it is major reason of contract) are mentioned. But some of jurists and writers, consider the verdict of civil law artic les (like articles 353,355 and 361) based on the theory of " mistakes in reason". Distinguishing the commitmentand deal reason, is in fact result of criticisms on the theory of mistakes in reason. So that the problems with this theory, made some writers distinguish between cause and reason and consider only mistakes in cause related to main features of contract and an obstruction to mutual consent.(Shahidi, 1380,360).

In defining the reason, it is stated that the deal reason is the direct or indirect goal or motivation of the deal which contract parties have when forming contracts. It is the final goal and it is by contract that a person wants to reach it. (Shahidi 1380,282). So, reasons are personal and private issues. This motivation or reason is different among people depending on personal situation or economic states. For example, when a person sells his house, the deal reason is perhaps buying another house or travelling and settling in another place. In other words, a mistake in reason is one in indirect motivation or with the mediu m of contract anda wrong thought that a person has, regarding forming a contract in order to reach their indirect motivation or with contract medium. (Safaee,1375,341). It is something that is a direct intention of the committed person and made him commit to 
form a contract. In other words, the goal why a person commit himself is the reason of commitment. (Safaee, 1351,100). The reason of commitment is the direct goal which makes any of contract parties commit to the other regarding contracts. This reason is always one thing and that is the other party's commitment regard ing the first one. For example, the reas on of a seller giving sale object to his costumer is getting payments with the costumer's commitment to pay the price. The reason of costumer's commitment to pay the price to a seller is becoming the owner of sale object and getting it from seller or commitment of seller on rendering the sale object to his costumer. This reason is always the same relating to all people in evidences of all types of contracts (Shahidi,1380,358). The reas on of nullifying the contract when there is a mistake in reason of commitment is that this kind of mistake has intertwined and firm relationship with determination and consent of contract parties and is the basis of mutual consents. (what was intended did not happen and what happened was not intended). This is unlike the deal reason and mistakes in it, which are personal issues and out of consent and domain of mutual consent of contract parties and has no effect in credits of contracts. So everything that, in opin ions of contract parties form the basis of contract formation and is the direct goal and the legal actshould be considered the main cause of contract, whether this basis is formed by the deal subject or contract partner or somebody except those two. (Safaee, 1382,88)

It seems that if we consider the basis of mistakes effects, their being substantial and basic, there is no difference in mistakes occurring in the contract subject or the contract party or in the reason of commitment; If the reason of deal, explicitly or implicitly enters the domain of mutual consent, mistakes result in nullification. So, since in all contracts, the main reason forms the base and substantial part of its making, any mistakes in them result in its nullification and loss of credits.

\section{The Mistake Resulting in the Cancel Right}

Iran civil law on one hand obeys the Imamieh Fiqh and pays serious attention to settlement and security of deals as a social profit, and on the other hand, respects freedom of people's resolution in performing deals and their consciousness. The total of these two interests makes it necessary that the nullification and non-influencing of the contracts are avoided. As a result, the major part of the effects of ignorance or mistakes in legal acts are mentioned in the frame of options and the loss sufferer is given the cancel right. For example, in mistakes regarding the economic value of the deal or fraud, or the mistakes resulting from defects and their likes. (Safaee, 88,1382) The main bases of cancelling option when there are results of mistakes are based on the dominance of one of the elements of " governing the office" and "no loss rule". (Katuzian,1376,57:5). So these mistakes do not harm the intention and are mostly formed for preventing the loss of contract partner.

1) Mistakes in price or the value of the deal object: If resulting in explicit fraud they give cancelling rights. (article 416 civil law).

2) Mistakes in secondary properties of the object of the deal and deal party: If they enter the domain of the deal implicitly or explicitly they give cancelling rights. These properties are of secondary types and result in more interest in dealing and affect the satisfaction. But they are not conditions of resolutions or the basis of the agreements of contract parties. (article 235,411 civil law). If secondary properties do not enter the domain of the contract, they do not result in the cancel rights and have no effects in the contract.

3) Mistakes in description of the completeness of the deal object: After the exchange contract, if the deal object is defective, obviously the imag ination of contract party from its completeness was wrong. For this reas on, the Imamie faqihs and subsequently the civil law gave the cancel right based on the no-loss rule or disregarding the condition. (Mohaqeq Damad, 1391,143:2).

\section{Ineffecti ve Mistakes}

Except the abovementioned issues, other mistakes have no effects in contracts and for settling the deals and jurists consider them trivial. For example, mistakes not resulting in explicit fraud or mistakes in the cause or the reasons of the deal which are personal and private is sues which make each of the contract parties do them. For example, someone buys a house to make huge benefits out of it, while he suffers losses, or an employee buys a house in his operation area in order to live in it while he is transferred to somewhere else. The reason of not nullifying of these mistakes is that the cause is private and variable and does not enter the contract and mutual consent domain. (Shahidi 116,1380).

So, it seems that mistakes in the secondary and causal is sues which are not mentioned in the contract and the contract is not based on their certainty and are not commonly considered defects, are not effective in contracts and do not result in nullify ing the contract. They do not harm the obligation of contracts either. Such mistakes have no effect on satisfaction and the contract, from the beginning has enough settlement and security. These 
mistakes must be corrected and with invoking to them nullification and non-influencing the contract is not possible.

\section{Conclusion}

In this article, it is assumed that the contract is established. Though the contract is the opposite of reality or there is an effective mistake on elements and main issues and its conditions. Our goal is reviewing the extent of effective mistakes on contract elements and main issues and contract conditions. In Iran law, contracts obey the obedient of intention. (Article 194 civil law),and also the intention and satisfaction of contract parties are of main conditions of correctness of the deal and they are the influencing conditions of the contract. (Article 190 civil law). In Islamic Fiqh, based on the fiqh rule " the contracts obeying the intentions", the contracts obey intentions. This rule has two meanings: a specific meaning stating that the identity of the contract obeys the intention and if there is no intention, there is no contract. (disagreement between compliance and acceptance). The other meaning is its general meaning of the "contracts" rule. This states that that obeying the types, effects, elements main issues and attributes of contracts are of intentions of contract parties. (what is intended did not happen and what happened was not intended). Based on this definition which this articles believes in, contracts obey contract parties. In fiqh and subsequently, Iran civil law, sometimes mistakes occur in basic and main issues of contracts and because of disturbance in intention, they result in nullifying the contracts. Sometimes, they occur in secondary issues of contracts and if they enter contracts, based on the no-loss rule and for compensating the losses, they give cancelling rights to the person who suffered the losses. Mistakes in trivial issues and non-existent in contracts have no effects in contracts. They will not result in nullify ing them nor will they bring cancel right for them. Based on this is sue, the nature of effects of effective mistakes in contracts in Iran fiqh and jurisprudence is categorized as: mistakes resulting in nullify ing contracts, mistakes giving the cancel rights to parties and mistakes having no effects.

Now there is a question: Is the domain of effective mistakes in legal issues limited to "contract types", "identity", "deal subjects", "contract parties", or commitment reasons ? ", or "can we say that mistakes in all main and primary aspects " results in nullifying the contract since they are under the domain of intention and mutual consent conditions and major reasons of contracts? Based on this issue, is the mistake domain is not restricted to specific issues?

The article 200 civil law limits the effective mistakes to "deal subject itself". Article 201 civil law states that mistakes are effective when they are of main reasons of contracts. Jurists have certain intentions in using the word itself. Via this, they state that mistakes are effective when they are related to "deal subject itself". Now what is meant by "itself" ? There are various views about this issue. Some state that it refers to object and constituting material of deal objects. Some other consider it the deal subject identity. In these two cases, contracts are nullified because of disagreement between compliance and acceptance. Some jurists consider the deal subject, " main issues " which are mutual consent conditions and main reason of contracts. Some other consider it the typical, common view of objects. This definition is affirmed by fiqh. The third definition of " main properties " is closer to parties' having resolutions and being neutral. Regarding mistakesin deal parties, just like the subject itself, they are considered evidences of mistake in main issues and the major reason of forming contracts. The contract is nullified because of them since they result in disagreement between compliance and agreement and contracts not obeying intentions. Only in one case, jurists made an exception in the main properties of people in "marriage contracts". For protecting the family and social interests, they gave cancel rights to it (article 1128 civil law).

Some writers distinguish between the "cause" and the reason of commitment and only consider the mistake in contract, which is typical and related to the its main elements, effective and an obstruction in mutual consent. The nullifying reason of contract in case of mistake in reason commitment, is when it forms the basis of mutual consent of parties. Not like the reason, which is a private issue and out of domain of agreement and mutual consent and basically has no effect on consent credits.

Regarding the obedience of contract type, features and its primary or secondary elements of contracting parties intentions, it seems that if we consider the basis of mistake effects, their being primary or fundamental, what is the difference in mistakes being in contract types, identities, deal subjects, contract parties or commitment reasons? As a general rule. we can say that if we consider the scale of identifying mistakes, their being fundamental. mistakes in all main issues which are conditions of mutual consents and main reasons of contracts nullify contracts since they harm intentions and mistakes in secondary issues, if mentioned in contracts, render the cancel right for the related person based on the "no-loss" rule. 


\section{References}

Adl, M. (1373). Civil Rights. Qazvin: Bahar.

Gharibe, A. (1386). Mistake in the contract. Journal oflawyers Association, 5\&6, 43-66.

Imami, H. (1378). Civil Rights. Tehran: Is la mia bookstore. First c. Twentieth Printing.

Jafari Langroodi, M. J. (1392). Will impact on civil rights (3rd ed.). Tehran treasure of knowledge.

Katoziyan, N. (1374). General rules of contract. Tehran: Publishing joint-stock company with Borna publication.

Katoziyan, N. (1376). General rules of contract (2nd ed.). Tehran, Publishing joint-stock company with Borna publication.

Mohaghegh Damad, Seyyed Mostafa Ghanavati, Jalil, Vahdati Shobeiri, Hassan and Abdi Poor fard, Abraham. (1391). Contract Law (2nd ed. Vol. 2).

Mousavi, M. S. (1393). Theoretical Foundations of ignorance and mistake it for legal acts and works (2nd ed.). Tehran: A mir Kab ir.

Rahpeyk, H. (1376). The theory in legal acts (1st ed.). Tehran: dissemination of information.

Safa'i, S. H. (1349). Wrong party to the contract. Faculty of Law and Political Science (Tehran University). No. 4. pp. 84-110.

Safai, S. H. (1351). The initial round of civil rights and obligations and contracts (Vol. 2). Tehran: Higher Institute of Accounting.

Safai, S. H. (1375). Articles about civil rights and comparative law (1st ed.). Tehran: Nshralmy zan.

Safai, S. H. (1382). Introductory courses of civil rights (general rules of contract) (1st ed.). Tehran: Mizan Publication.

Shahidi, M. (1377). Civil rights, individuals (with doctor Ghasemzadeh). Tehran: Organization of ICTS, (Samt)

Shahidi, M. (1380). Form contracts and obligations (2nd ed.). Tehran: Majd.

Zakeri, R. (1390). New Approach and Analysis of the error and its effect on the contract. Forozesh publication.

\section{Copyrights}

Copyright for this article is retained by the author(s), with first publication rights granted to the journal.

This is an open-access article distributed under the terms and conditions of the Creative Commons Attribution license (http://creativecommons.org/licenses/by/4.0/). 